\title{
ACESSIBILIDADE EM INSTITUIÇÕES DE ENSINO SUPERIOR - RESIDÊNCIA UNIVERSITÁRIA 125/ UFC
}

\author{
SILVEIRA, Plínio \\ Universidade Federal do Ceará, e-mail: pliniorenan@gmail.com \\ SANTIAGO, Zilsa \\ Universidade Federal do Ceará, e-mail: zilsa@arquitetura.ufc.br \\ MORANO, Raquel \\ Universidade Federal do Ceará, e-mail: raquelmorano20@gmail.com
}

\begin{abstract}
RESUMO
Este trabalho faz parte de uma pesquisa sobre acessibilidade em instituições de ensino superior que se encontra em fase de análise dos primeiros resultados. Na questão do acesso de pessoas com deficiência (PCD) nos ambientes universitários vislumbra-se mudança de paradigma com a sanção da Lei 13.409 de 28 de dezembro de 2016, que dispõe "sobre a reserva de vagas para PCD nos cursos técnico de nível médio e superior das instituições federais de ensino" (BRASIL, 2016), ampliando as matrículas de PCD no ensino superior. Neste sentido, o objetivo deste paper é apresentar parte dos resultados da investigação sobre as condições de acessibilidade espacial nos edifícios universitários, tendo como recorte espacial a Universidade Federal do Ceará, mais especificamente, a Residência Universitária 125 localizada no bairro do Benfica, por ser uma edificação importante da arquitetura moderna em Fortaleza. A metodologia foi de caráter qualitativo exploratório por meio da Avaliação Pós-Ocupação (APO) (ORNSTEIN, 1992; PREISER; RABINOWITZ; WHITE, 1988). Como resultado, foi possível verificar a situação da edificação em relação às diretrizes do desenho universal, bem como, e apontar os desafios para intervenções futuras.
\end{abstract}

Palavras-chave: Edifícios universitários, Acessibilidade, Avaliação Pós-Ocupação.

\begin{abstract}
This paper is part of a research on accessibility conditions in Higher Education Institutions which is in analysis' phase of the first results. In the matter of the access of persons with disabilities (PWD) in University environments there is a paradigm shift with the sanction of the Law 13,409 from December 28th, 2016, amending Law 12,711 "to provide vacancies' reservations for PwD in middle and upper level technical courses of the federal institutions of education" (BRAZIL, 2016), aiming, so expand access of PwD in Federal Universities. This way, the objective of this paper is to present part of the research's results on spatial accessibility conditions in University buildings, with the Federal University of Ceará as study site, more specifically, the University Residence located in Benfica neighborhood, being an important building of modern architecture in Fortaleza. The methodology was of qualitative exploratory character, and the post-occupancy evaluation (POE) (ORNSTEIN, 1992; PREISER; RABINOWITZ; WHITE, 19881988) was used to analyze the building. As a result, it was possible to check the situation of the building in relation to universal design guidelines, as well as how these results can be used to direct future interventions.
\end{abstract}

Keywords: University Buildings, Accessibility, Post-Occupancy Evaluation.

\section{INTRODUÇÃO}

Contextualizando o problema do acesso de Pessoas com Deficiência nos ambientes universitários, vislumbra-se da mudança de paradigma com a

SILVEIRA, P.; SANTIAGO, Z.; MORANO, R. Acessibilidade em instituições de ensino superior Residência Universitária 125/ UFC. In: SIMPÓSIO BRASILEIRO DE QUALIDADE DO PROJETO NO AMBIENTE CONSTRUÍDO, 6., 2019, Uberlândia. Anais... Uberlândia: PPGAU/FAUeD/UFU, 2019. p. 862-871. DOl https://doi.org/10.14393/sbqp19080. 
sanção da Lei 13.409 de 28 de dezembro de 2016, que altera a Lei de cotas, "para dispor sobre a reserva de vagas para pessoas com deficiência nos cursos técnico de nível médio e superior das instituições federais de ensino" (BRASIL, 2016), ampliando as matrículas de PCD no ensino superior. Esta lei representa um marco da inclusão ao desfazer uma barreira histórica de desvantagem neste acesso.

As "cotas" no ensino superior representam grande avanço para as PcD no que diz respeito à equiparação de direitos, porém, nos coloca uma reflexão: as instituições federais de ensino superior, cuja infraestrutura foi, em grande parte, concebida e construída em décadas anteriores à legislação de acessibilidade, encontram-se estruturalmente preparadas para 0 ingresso destes estudantes?

Neste sentido, o objetivo deste trabalho é analisar a qualidade do ambiente com o intuito de entender a situação atual da acessibilidade em edifícios universitários dentro deste novo contexto que se apresenta. Acrescenta-se que alguns edifícios destas instituições, a exemplo do edifício em estudo, possuem valor patrimonial e cujas adaptações devem compatibilizar as diretrizes do desenho universal e a atenção à memória do edifício.

\section{METODOLOGIA}

A elaboração deste trabalho constitui-se: 1. na pesquisa documental a fim de resgatar o histórico do edifício e entendimento de sua concepção, bem como as intervenções que ocorreram ao longo dos anos; 2 . em dados e levantamentos realizados na pesquisa de campo, fundamentada na metodologia da Avaliação Pós-Ocupação - APO, um campo de pesquisa aplicada constituído de métodos e técnicas de características quantitativas/ qualitativas e que têm por objetivo a avaliação sistemática de ambientes construídos. A Avaliação Pós-Ocupação (ORNSTEIN, 1992) é o processo de coleta de dados, análise e comparação com critérios de performance explicitamente declarados, de ambientes construídos e ocupados (PREISER; RABINOWITZ; , 1998). Essa metodologia busca identificar aspectos negativos e positivos da edificação, e elaborar sugestões que possam contribuir para minimizar ou solucionar os problemas existentes.

Com a realização de visitas a todos os ambientes da edificação selecionada é analisada a sua condição de adequação ou não às normas vigentes. Para isso, fez-se o levantamento arquitetônico dos ambientes gerais, tais como: salas de estudo; espaços convivência; copa; banheiros e ambientes administrativos, como também dos ambientes de moradia - quartos e banheiros.

Os critérios avaliados variam conforme cada ambiente, e abrangem características, como: comunicação visual; comunicação em Braille; dimensão de vão das portas de acesso aos ambientes; tipos de maçaneta; presença de desnível no acesso; presença e adequação de rampas; condições de piso; contraste de cor entre piso e parede; altura de mesas; bancos e cadeiras; alturas de lavatórios; tipos de maçanetas; presença e adequação de barras de apoio em banheiros.

Nesta pesquisa, a avaliação do espaço tem como objetivo identificar os elementos pertinentes à acessibilidade, diagnosticando barreiras 
arquitetônicas e urbanísticas e identificando elementos ou rotas acessíveis. Esta análise foi realizada através de checklists, anotações e registros fotográficos, tendo como critérios principais os parâmetros estabelecidos na NBR9050/2015, NBR16537/2016, Decreto 5.296/2004, dentre outras regulações. Parte da coleta foi realizada pelos estudantes de graduação em arquitetura e urbanismo na Disciplina de Desenho Universal em 2018.2.

\section{RESIDÊNCIA UNIVERSITÁRIA - BENFICA}

Na década de 1950, com a volta de arquitetos, que tiveram sua formação no Rio de Janeiro e Recife, ao Ceará, inicia-se a produção arquitetônica por profissionais com formação acadêmica em Arquitetura no Estado, indo ao encontro dos anseios de modernização da sociedade fortalezense (JUCÁ NETO et al., 2009). Grande parte desta produção inicial modernista corresponde a edifícios da UFC, a exemplo da Residência Universitária (REU 125).

O edifício foi projetado pelo arquiteto Ivan da Silva Britto, para o logradouro Paulino Nogueira, n. 125, entre a Rua Waldery Uchoa e a Rua João Gentil, no Bairro Benfica (Figura 1), em frente à Praça José Gentil, com objetivo de propiciar a permanência do estudante - em situação de vulnerabilidade socioeconômica - oriundo do interior do Estado, ou de outros estados, na UFC. Sua inauguração data do ano de 1966.

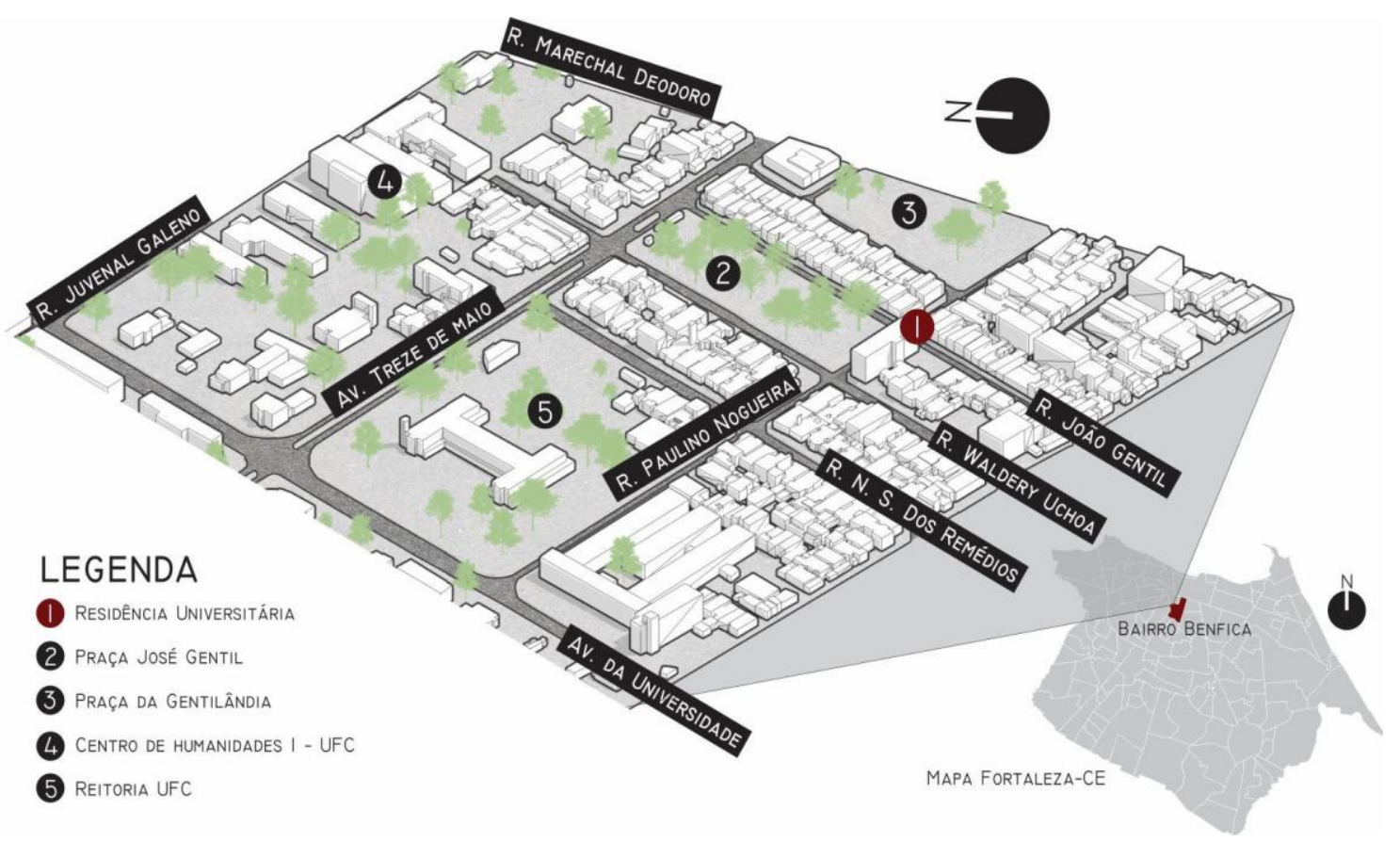

Figura 1 - Mapa ilustrativo de localização da Residência Universitária Fonte: Modelagem de Mirella Raposo com edição dos autores (2019)

Segundo Jucá Neto et al. (2009), no projeto original da residência universitária estavam previstos seis pavimentos, mas a edificação foi construída apenas com quatro pavimentos. O pavimento térreo é composto por uma área sob pilotis, áreas de convivência, lavanderia e banheiros coletivos e um hall de entrada com a circulação vertical de acesso aos demais pavimentos. No primeiro pavimento foram dispostos os ambientes de uso comum e 
administrativo. $O$ segundo e terceiro pavimentos (pavimento tipo) correspondem aos dormitórios dos estudantes.

A forma que se destaca no edifício é a de um prisma retangular flutuante (predomina a horizontalidade, assim como as demais edificações modernistas da Universidade), acentuado pelo fato de que o térreo e o primeiro pavimento encontram-se recuados em relação à caixa maior (do $2^{\circ}$ e $3^{\circ}$ pavimento), garantindo leveza à edificação. Seu sistema estrutural é de lajes, vigas e pilares de concreto dispostos em modulação de 5,70 metros no eixo longitudinal (Figura 2).
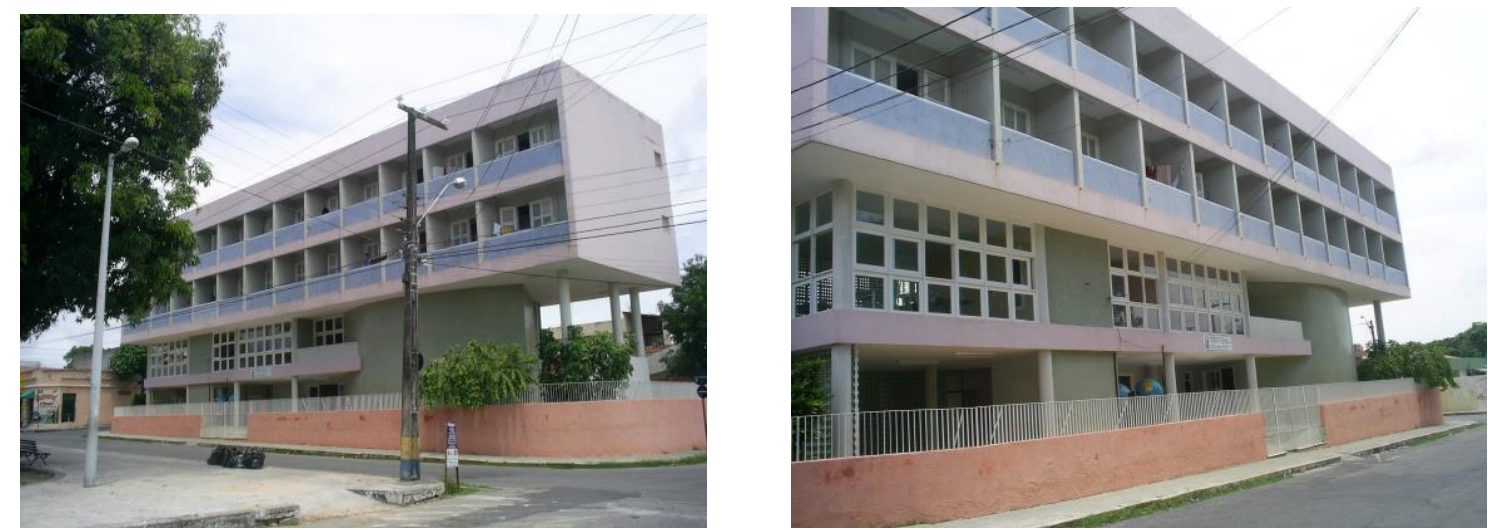

Figuras 2 e 3 - Residência Universitária -

Fonte: Autores (2010)

A edificação passou por diversas alterações do projeto original. Na década de 90 houve uma grande reforma de recuperação. Posteriormente, novas intervenções foram realizadas no edifício, sendo as mais relevantes aquelas relacionadas à acessibilidade, a fim de possibilitar o livre acesso de pessoas com deficiência.

\section{ANÁLISE DA RESIDÊNCIA UNIVERSITÁRIA - BENFICA}

A análise da Residência 125 quanto à acessibilidade se inicia no entorno e acesso ao edifício situado na Rua Paulino Nogueira. Por iniciativa da Prefeitura de Fortaleza foi construída uma faixa elevada de travessiai, ligando a Praça José Gentil e a calçada da residência contendo piso tátil direcional até o muro da edificação e possibilitando assim o acesso de pessoas com deficiência física e visual, por meio da referência edificada (Figura 4). O piso tátil, porém, não possui contraste de luminância em relação ao piso adjacente, limitando o uso por pessoas com baixa visão, que utilizam a visão residual para sua locomoção.

A calçada da residência, em piso cimentado, apresenta boas condições de acessibilidade, possibilitando uma rota acessível até o acesso principal. Neste acesso, os desníveis foram adaptados com a construção de rampas (Figura 7). A figura 5 mostra a rampa construída para realizar a concordância do nível da calçada para o nível do jardim, $7 \mathrm{~cm}$ mais alto. A rampa foi construída contígua ao portão, sem patamar que possibilite sua abertura com independência para pessoas em cadeira de rodas. Na calçada foi construído um rebaixo para o nível da rua sem as abas laterais.

O acesso do nível do jardim para o pilotis (Figura 7), realizado originalmente por escadarias, foi também solucionado pela adição de uma rampa (Figura 
6). Esta, porém, possui inclinação acima da máxima estabelecida na NBR9050, limitando a autonomia de pessoas com restrições motoras. Soma-se que os corrimãos encontram-se fora dos padrões normativos, não possui guia de balizamento em todo o trecho de rampa e não apresenta sinalização de corrimão, bem como sinalização tátil de alerta em seu início e final.

$\mathrm{Na}$ escadaria, foram adicionadas faixas de fita antiderrapante para melhorar a aderência do piso de mármore dos degraus, porém, a ausência de corrimãos dificulta a transposição de nível. Também não apresenta piso tátil alerta em seu início e final.

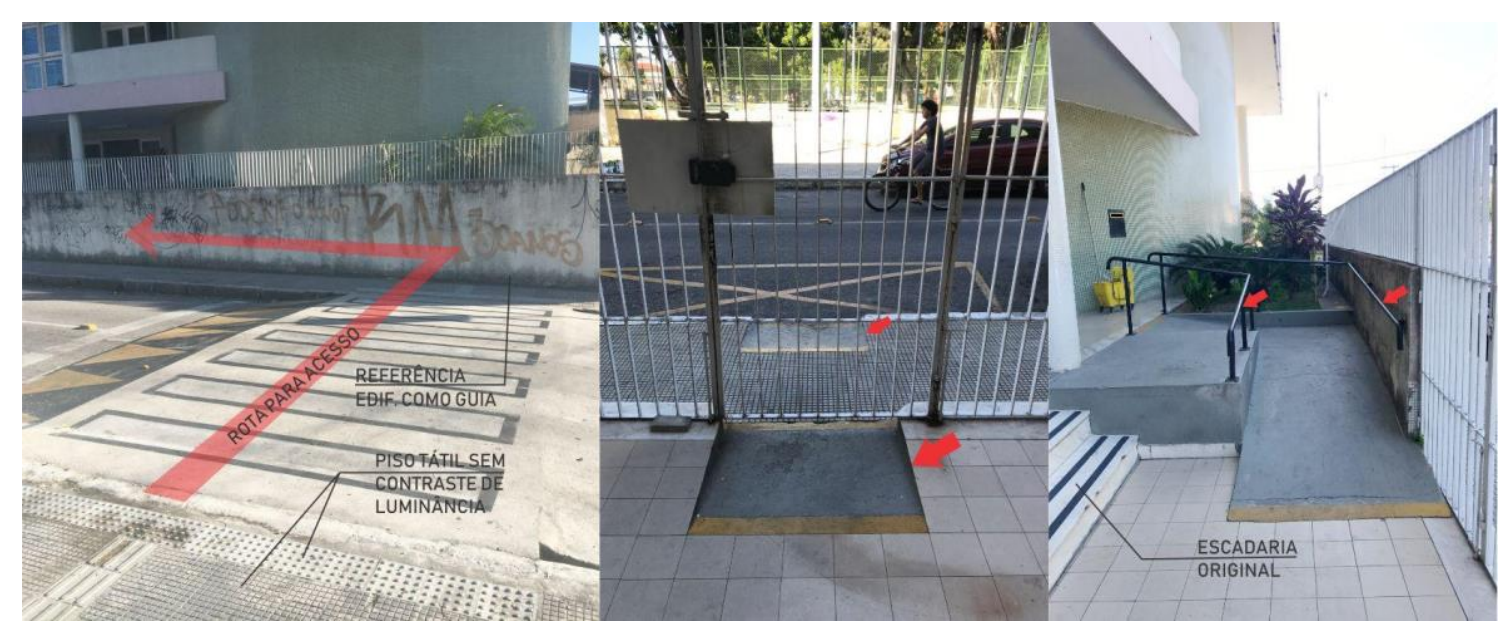

Figuras 4, 5 e 6 - Faixa elevada, rampa para jardim, rampa para pilotis -

Fonte: Acervo da Disciplina de Desenho Universal - Curso de Arquitetura e Urbanismo UFC (2018)

A área do pilotis e de um salão contíguo são utilizadas como espaços de convivência. No acesso a este salão, há um desnível de $2 \mathrm{~cm}$ na soleira. Os espaços são amplos e não apresentam rota tátil aos pontos de interesse, por exemplo, ligando o acesso principal à mesa da recepção (Figura 8).

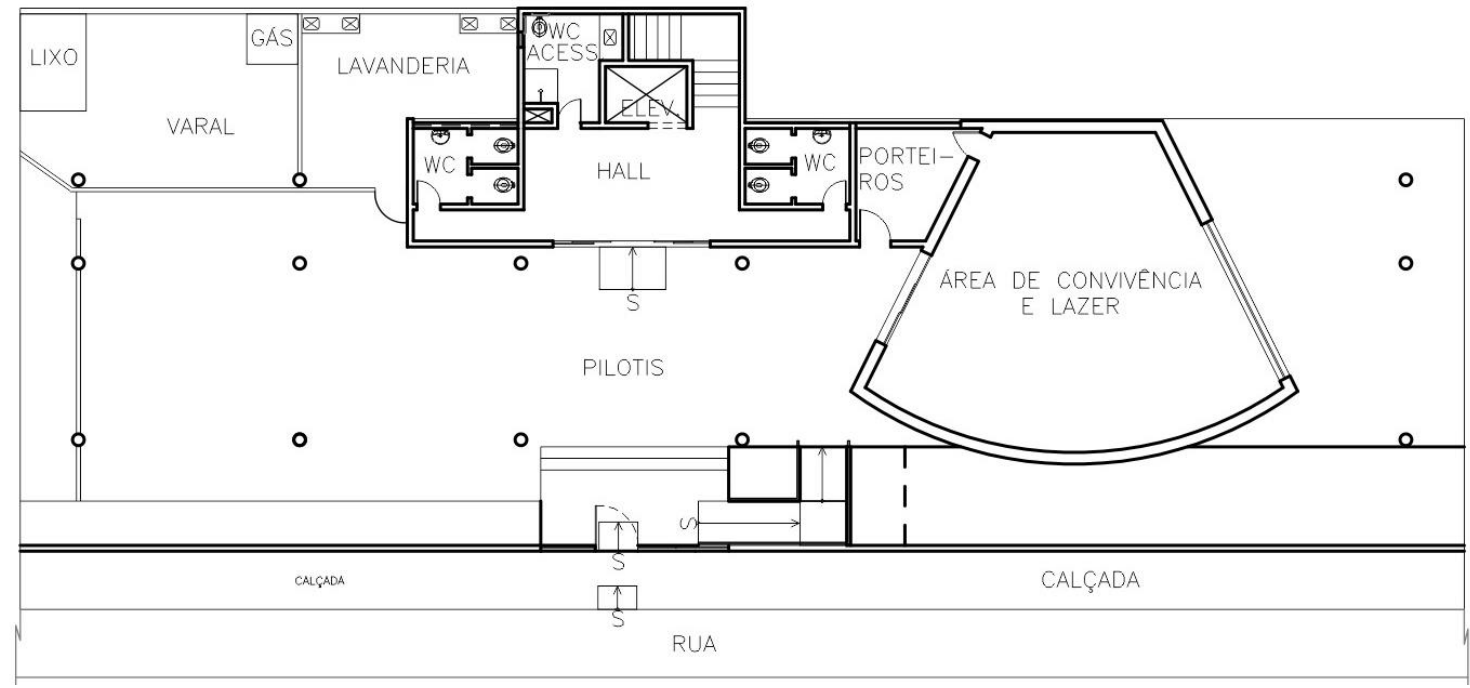

Figura 7 - Planta baixa do térreo -

Fonte: UFC Infra (2017)

A edificação também não apresenta mapa tátil. No pilotis, existem "orelhões" que, pelo volume superior suspenso, representam riscos para pessoas cegas. Os "orelhões" apresentam altura da botoeira fora da faixa de alcance para pessoas em cadeira de rodas (Figura 8). 
Parte do piso original do pilotis foi substituído por cerâmica lisa, o que, em dias de chuva ou limpeza, oferece risco de acidentes. Do nível do pilotis para o hall do térreo, outro desnível foi solucionado através de rampa, em que se utilizou faixas de fita antiderrapante para melhorar a aderência da cerâmica, porém possui inclinação superior à máxima permitida na NBR9050 e faltam outros itens obrigatórios como corrimãos, guia de balizamento e sinalização (Figura 9).

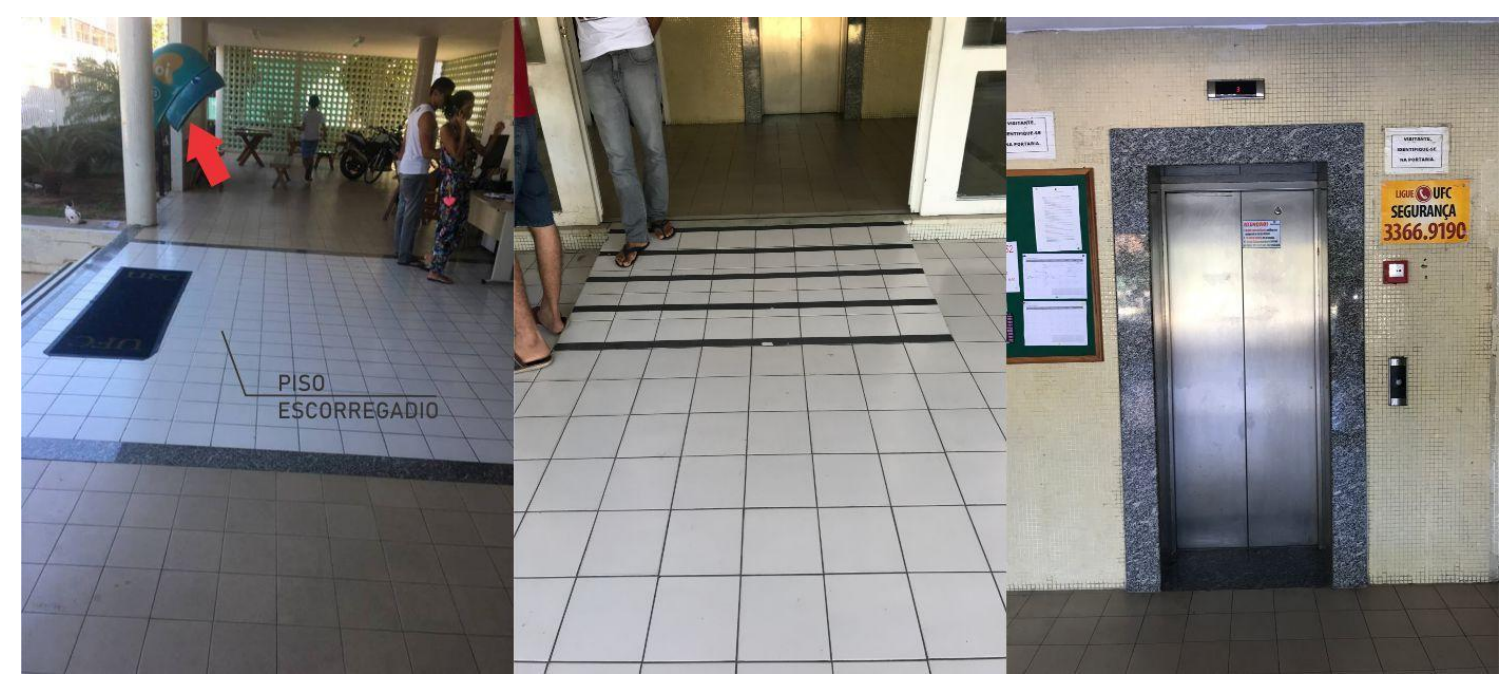

Figuras 8, 9 e 10 - Área dos pilotis, rampa para hall, elevador -

Fonte: Acervo da Disciplina de Desenho Universal - Curso de Arquitetura e Urbanismo UFC (2018)

Na área do hall, utilizou-se um vazio existente na caixa da escada original para instalação de elevador, comunicando térreo, $1^{\circ}, 2^{\circ}$ e $3^{\circ}$ pavimentos, possibilitando assim o acesso universal aos dormitórios e áreas comuns do edifício. (Figura 10). Não há sinalização tátil de alerta, nem sinalização de pavimentos na escada e no elevador.

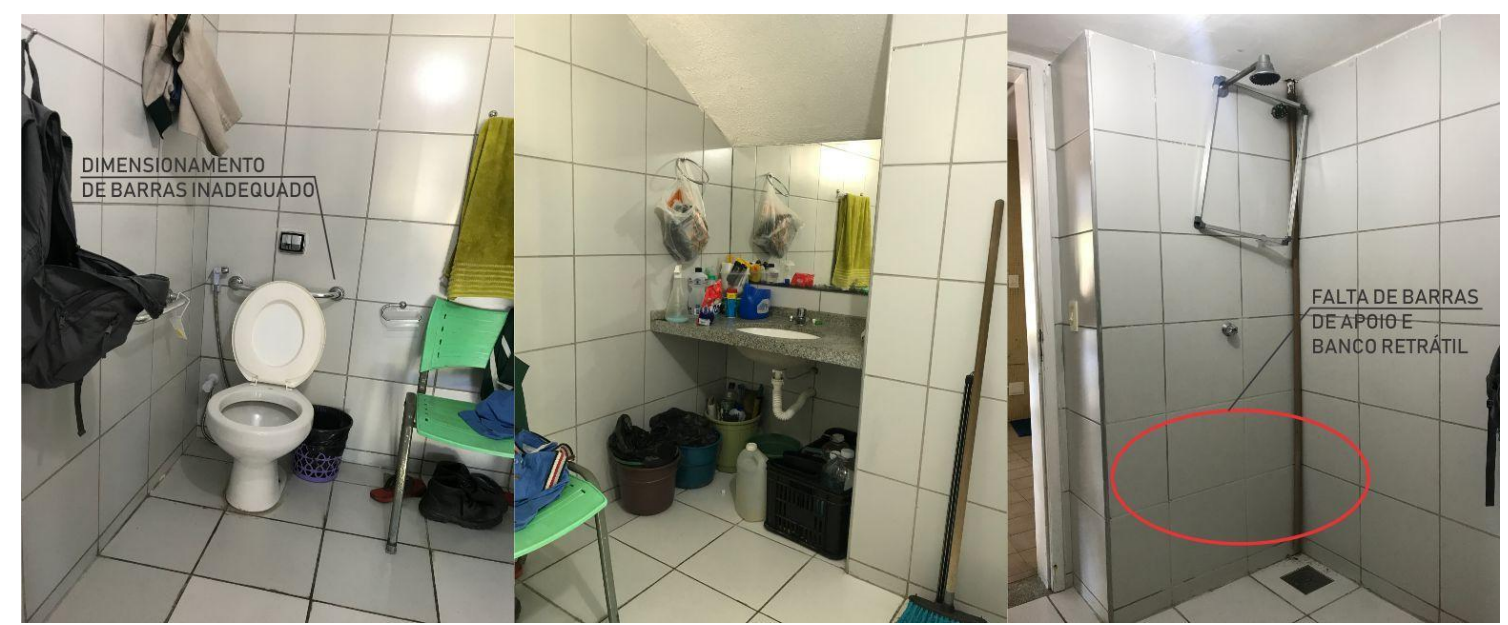

Figuras 11, 12 e 13- Bacia sanitária, lavatório e chuveiro no banheiro acessível térreo -

Fonte: Acervo da Disciplina de Desenho Universal - Curso de Arquitetura e Urbanismo UFC (2018)

O hall também dá acesso aos banheiros sociais e à lavanderia. Um dos espaços foi reformado para receber um banheiro acessível. O espaço possui áreas de circulação adequadas para pessoas em cadeiras de rodas, porém foram encontradas inadequações de acessibilidade como a porta abrindo para dentro do ambiente, dimensionamento inapropriado de barras, lavatório sem barras de apoio, desnível para área do chuveiro, chuveiro sem barras de 
apoio e sem banco retrátil para transferência (Figuras 11, 12 e 13). Acrescentase que o depósito de alguns materiais na área do banheiro também restringe a autonomia de uso para algumas pessoas com deficiência, interferindo por exemplo na área de manobra de pessoas em cadeiras de rodas.

No primeiro pavimento (Figura 14), situam-se os espaços de uso comum dos estudantes: duas salas de estudos; uma sala de leitura; uma sala de informática e uma copa, bem como, áreas administrativas e dois banheiros. Este pavimento não possui banheiro acessível.

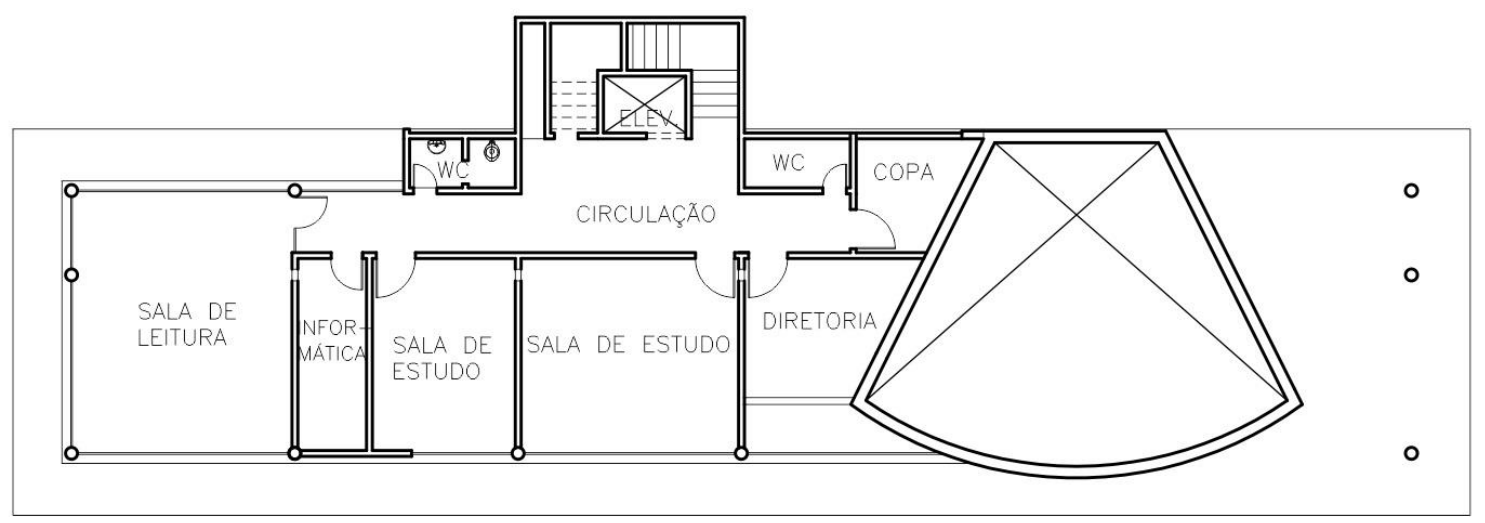

Figura 14 - Planta baixa do $1^{\text {a }}$ pavimento -

Fonte: UFC Infra (2017)

As áreas de estudo e leitura são amplas e não possuem rota tátil até o mobiliário (Figura 15). As mesas possuem altura livre inferior que permite a aproximação frontal de uma pessoa em cadeira de rodas. O mesmo não ocorre na sala de informática, cuja altura livre de apenas $68 \mathrm{~cm}$ impossibilita 0 uso por estas pessoas (Figura 16). Soma-se que existe desnível de $2 \mathrm{~cm}$ na soleira da porta desta sala. A copa também não permite o uso para pessoas em cadeira de rodas devido à altura da bancada, e não possibilita aproximação frontal para utilização da mesa existente (Figura 17).

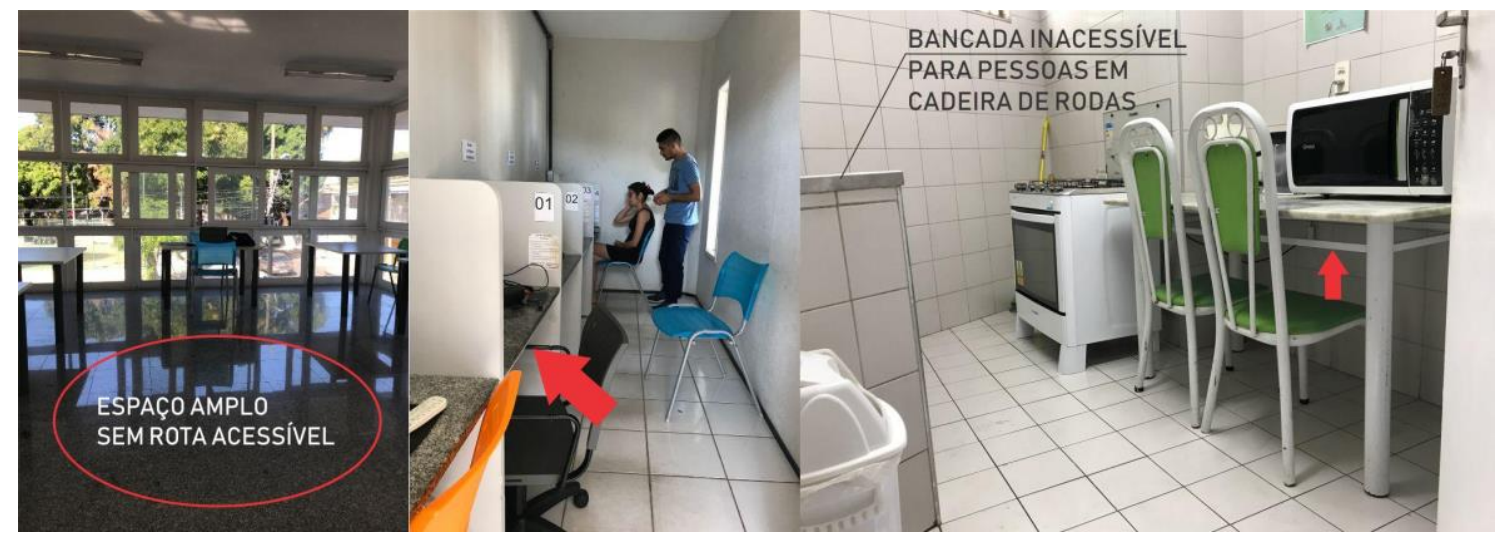

Figuras 15, 16 e 17 - Área de estudos, sala de informática, copa -

Fonte: Acervo da Disciplina de Desenho Universal - Curso de Arquitetura e Urbanismo UFC (2018)

O segundo e terceiro pavimentos correspondem ao pavimento tipo (Figura 18) e abrigam os dormitórios dos estudantes. Estes pavimentos avançam sobre os dois inferiores e configuram o volume principal da edificação. A adaptação para acessibilidade foi possível devido a configuração da planta original, pois os apartamentos das extremidades, nos dois pavimentos, foram projetados mais amplos para abrigar um número maior de estudantes. 


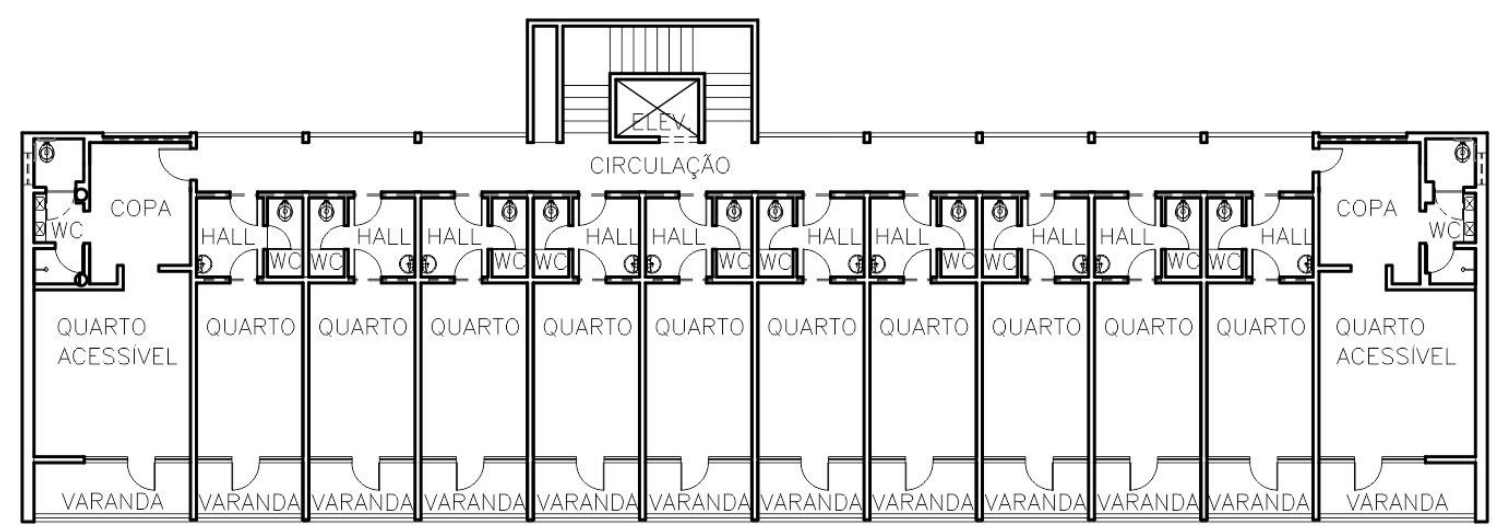

Figura 18 - Planta baixa do pavimento-tipo -

Fonte: UFC Infra (2017)

A análise encontrou inadequações nos quartos acessíveis que podem inviabilizar ou limitar a autonomia de pessoas com deficiência. Existe desnível nas portas solucionados com rampas fora dos padrões de inclinação e sem patamar para possibilitar alcance de abertura da porta com autonomia (Figura 19). A bancada de estudos não permite aproximação frontal de pessoas em cadeira de rodas devido à altura e uma base de concreto no piso (Figura 20). O acesso à varanda acontece por uma porta com vão de apenas 0,66 m (Figura 20). Na copa, o mobiliário existente não permite a aproximação frontal de pessoas em cadeiras de rodas, inviabilizando seu uso (Figura 21).

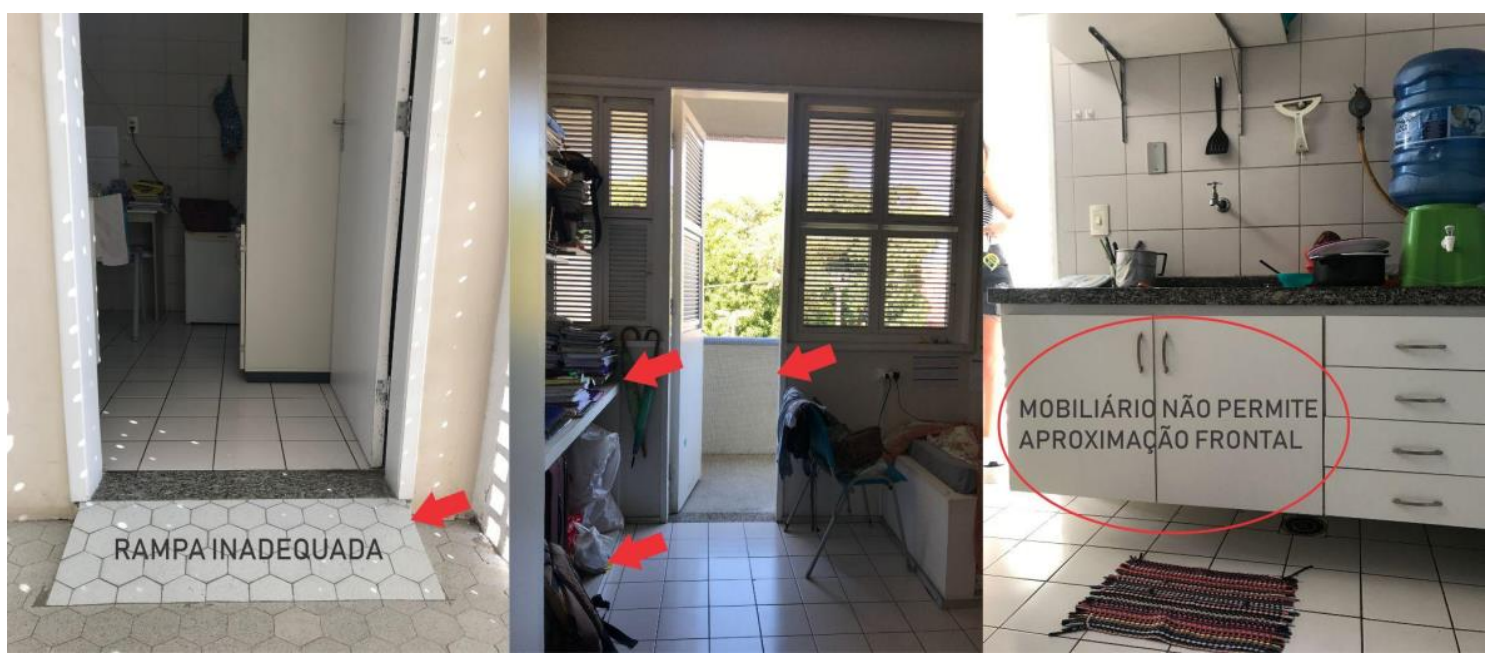

Figuras 19, 20 e 21 - Rampa, bancada e acesso à varanda, copa do dormitório acessível -

Fonte: Acervo da Disciplina de Desenho Universal - Curso de Arquitetura e Urbanismo UFC (2018)

No espaço dos dormitórios, as camas possuem altura inadequada para realização da transferência de uma pessoa em cadeira de rodas. No $3^{\circ}$ pavimento, agrava-se devido à falta de área para circulação de pessoas em cadeira de rodas (Figura 24).

Nos banheiros destas acomodações, verificou-se o dimensionamento inapropriado da área necessária para circulação, transferência para bacia sanitária e uso do chuveiro. Também constatou-se: barras com dimensionamento fora dos padrões (Figuras 22); ausência de barras nos lavatórios, ausência de barras e banco articulado na área dos chuveiros (Figura 23). 

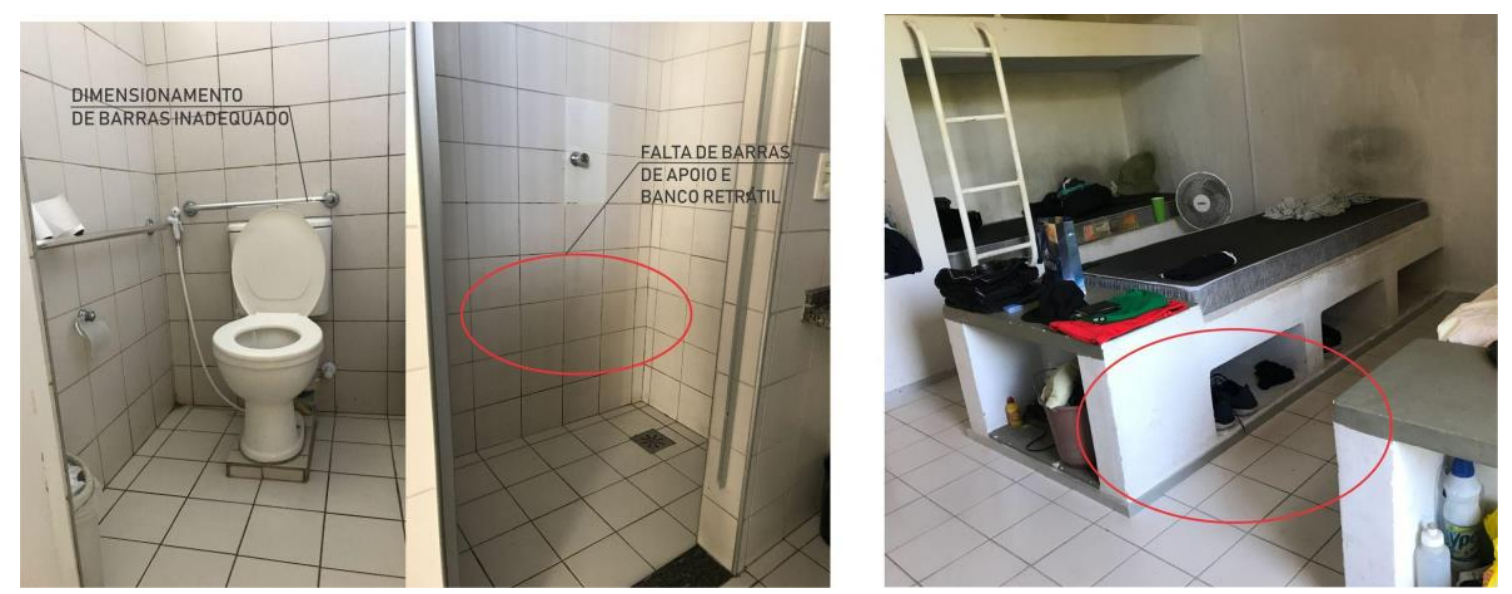

Figuras 22, 23 e 24 - Sanitário, área do chuveiro, área do dormitório -

Fonte: Disciplina de Desenho Universal - Curso de Arquitetura e Urbanismo UFC (2018)

Desta forma, embora essas unidades tenham passado por adaptações, não possibilitam o uso a qual foi destinado para todas as pessoas. Considera-se que o tipo de equipamento avaliado oferece um serviço de grande importância no âmbito da universidade para o público discente, o que torna ainda mais importante a democratização de acesso, uso e permanência desses espaços, que precisam receber adequadamente qualquer pessoa, inclusive com deficiência ou mobilidade reduzida.

\section{CONSIDERAÇÕES FINAIS}

Com a institucionalização das normas de acessibilidade, tornou-se obrigatória a adaptação das edificações de uso público, o que ocasionou uma série de interferências em edifícios antigos e que, a exemplo da REU 125, possui um reconhecido valor patrimonial. Como o edifício não possui tombamento, cujo processo diferenciado de adaptação obedece a ressalvas específicas do IPHAN, é preciso encontrar um meio termo para que se respeite as características do edifício e ao mesmo tempo, seja permitido o acesso universal.

É perceptível que houve uma preocupação quanto à acessibilidade nos ambientes gerais da residência universitária em estudo, um exemplar da arquitetura moderna, e cujo projeto original não previa estas questões. A amplitude de concepção espacial generosa favoreceu acomodar de forma confortável as novas configurações e elementos destinados a criar acesso e condições de permanência de pessoas com deficiência e mobilidade reduzida nos ambientes do referido prédio.

A análise mais aprofundada entretanto, aponta algumas questões que precisam ser equacionadas para que a residência possibilite pleno uso para todas as pessoas com conforto, segurança e autonomia. A partir da análise dos pontos principais concernentes à acessibilidade, tais como: a falta de rota acessível demarcada, principalmente em áreas mais amplas como no pilotis e alguns espaços comuns; ausência de pisos táteis alerta em locais de risco, como escadas, portas do elevador, em elementos suspensos; ausência de mapa tátil e comunicação visual e tátil nos ambientes: portas, escada e elevador; ausência de banheiro acessível no $1^{a}$ pavimento; inadequações no dimensionamento de barras nos banheiros; ausência de bancos articulados nos chuveiros; alturas inapropriadas de lavatórios; inadequações no mobiliário. 
Os resultados desta pesquisa fornecem subsídios e recomendações acerca da acessibilidade física da Residência Universitária, bem como demonstram o quanto o ambiente universitário, principalmente o que se destina a acomodar estudantes em moradia temporária em Fortaleza já passou por transformações de inclusão de novos elementos, contudo, ainda não garante plena acessibilidade física, e demanda, portanto, que profissionais com conhecimento das normas relativas ao tema sejam consultados para possíveis reformas.

Acrescenta-se por fim, que o tipo de uso da Residência, que manteve-se ao longo das décadas, possibilitou a maior conservação das características do edifício, diferente de outras edificações modernas da UFC, cujas mudanças de uso repercutiram em descaracterizações dos projetos originais. Esta análise conclui também que as intervenções de acessibilidade realizadas tiveram um razoável respeito às características do edifício, porém existem lacunas a serem solucionadas, conforme destacado acima.

\section{REFERÊNCIAS}

ASSOCIAÇÃO BRASILEIRA DE NORMAS TÉCNICAS. NBR 9050: Acessibilidade a edificações, mobiliário, espaços e equipamentos urbanos. Rio de Janeiro, 2015.

ASSOCIAÇÃO BRASILEIRA DE NORMAS TÉCNICAS. NBR16537/2016:

Acessibilidade - Sinalização tátil no piso - Diretrizes para elaboração de projetos e instalação.

BRASIL. Lei N 13.409, de 28 de dezembro de 2016. Brasília, DF, 2016.

BRASIL. Decreto $N^{\circ}$ 5.296, de 2 de dezembro de 2004, que regulamenta as Leis $n^{\circ} \mathrm{s} 10.048$, de 8 de novembro de 2000, que dá prioridade de atendimento às pessoas que especifica, e 10.098, de 19 de dezembro de 2000, que estabelece normas gerais e critérios básicos para a promoção da acessibilidade das pessoas com deficiência ou com mobilidade reduzida, e dá outras providências.

JUCÁ NETO, C. R.; FERNANDES, R.; NASCIMENTO, J. C.; ANDRADE, M. J. S.;

DIÓGENES, B. H. N. A Universidade e a cidade - Por uma história da Arquitetura Moderna da Universidade Federal do Ceará. In: Anais do $8^{\circ}$ DOCOMOMO

BRASIL. Rio de Janeiro, 2009.

ORNSTEIN, S. W; ROMÉRO, M. (Colaborador). Avaliação Pós-Ocupação (APO) do ambiente construído. São Paulo: Studio Nobel: Editora da Universidade de São Paulo, 1992, p. 15.

PREISER, W. F. E; RABINOWITZ, H. Z.; WHITE, E. T. Post Occupancy Evaluation. Nova York: Van Nostrand Reinhold, 1988.

\footnotetext{
i Essa faixa elevada faz parte do Plano de Segurança Viária da Prefeitura de Fortaleza, que vem investindo em medidas que resultam em mais segurança no trânsito para pedestres e pessoas com mobilidade reduzida, com o objetivo de reduzir a quantidade e a severidade dos acidentes de trânsito. As ações são coordenadas pela Secretaria Municipal de Conservação e Serviços Públicos (SCSP), como parte do Programa de Apoio aos Pedestres, desenvolvido pelo Plano de Ações Imediatas de Transporte e Trânsito de Fortaleza (PAITT). Estas intervenções fazem parte do pacote de atividades desenvolvidas em parceria com a Iniciativa Bloomberg Philanthropies em Fortaleza e atendem a uma resolução do Conselho Nacional de Trânsito (Contran).
} 